Brock Education, Vol 18, 2008

\title{
Martial Arts, Violence, and Public Schools
}

\author{
Chunlei Lu: Brock University, Canada
}

\begin{abstract}
Martial arts have become one of the most popular physical activities amongst children and youth worldwide; however, there are concerns among Western parents and school administrators that including these activities in school programs may lead to incidents of violence. Others, however, maintain that this is a concern caused by the false image of martial arts (as propagated in entertainment and pop culture), and stemming from an ignorance of the true values promoted by legitimate Asian martial arts practitioners. This paper explores the philosophical and theoretical concepts upon which Asian martial arts disciplines are founded, and provides ample research to reveal that martial arts as practiced in Eastern tradition de-emphasize violence, competition, and combat. Further, this paper illustrates that practicing martial arts in line with Eastern precepts of martial virtue, promotes a healthy active lifestyle, and can in fact discourage, rather than encourage, incidents of violence at schools.
\end{abstract}

\section{Introduction}

While martial arts have become one of the most popular physical activities among millions of children and youth around the world (De Knop, Engstrom, Skirstad, \& Weiss, 1996), there have been concerns among Western parents, teachers, and school administrators that violence could potentially arise in schools and communities as a result of teaching martial arts in school programs (Lu, 2004). The Journal of Physical Education, Recreation, and Dance (JOPERD) (an influential journal in the Western physical education field) discussed the question "Should martial arts be taught in physical education classes?" in its November/December 2000 issue. Illustrating the prevalence of this controversy, the forum was eagerly taken up by critics who expressed serious concerns regarding potential violence or discipline problems associated with introducing martial arts to schools; these concerns were just as readily contradicted by proponents of martial arts who had research evidence to support their arguments that violence and martial arts do not commonly go hand in hand. In contrast, martial arts in the East, whence they originated, have long been a required component in physical education curricula in, for example, China and Japan; and millions of people of all ages always practice martial arts on a regular basis (Lu, 2004; Sasaki, 2006). This paper will examine the reasons for perceived violence associated with martial arts, the theoretical foundation of martial arts, and the function of martial arts in reduction of violence. The purpose of the paper is to equip school educators (e.g., health and physical educators) with legitimacies to integrate martial arts into their programs in order to assist children and youth to reduce violence, enhance moral development, and foster a healthy active lifestyle.

\section{What are martial arts?}

Generally speaking, martial arts are a system of codified combative movements intended to defeat an opponent or to defend oneself from physical threat. While there are many types of martial arts practiced world-wide, Eastern or Asian martial arts are 
regarded as the most influential, in particular, the Chinese, Korean, and Japanese martial arts (e.g., judo, karate, taekwondo, taijiquan, wushu) that distinguish themselves with their theoretical foundation of Eastern philosophies. Most Eastern martial arts originated in China (Theeboom \& De Knop, 1999) and draw heavily upon Chinese philosophy (Johnson \& Brown, 2000; Kauz, 1977). Not to be confused with what in the West may be perceived as "physical" activities, Eastern martial arts are instead "philosophical" and "mindful" activities, and are regarded as moving philosophies. In the contemporary world, these Eastern martial arts are the predominant forms in commercial and public school martial arts programs.

\section{Why are martial arts associated with violence}

There are two potential reasons behind the concern that teaching martial arts fosters violence: ignorance, resulting from the lack of knowledge of the nature of martial arts; and misunderstanding, due to misleading representations of the Westernized martial arts through commercialized media. For instance, movies and television have been accused of disseminating the negative, violent image of martial arts, while simultaneously being credited for popularizing them. Commercialization paved the way for martial arts to take their featured place in show business, but has brutalized and distorted their image in the process (Cox, 1993). Full-contact Karate is a perfect example (Forster, 1986), and the transition of the martial arts to martial "sport" adds another negative impact (see more information in the section of "Modern Westernized Eastern martial arts" below). In addition, the very words "martial arts," to many people, literally translate as "fighting skills" (the word "martial" derives from the name of Mars, the Roman god of war). As early as the 1970s, Min points out that the initial popularity of martial arts is

perhaps not hard to account for since the blatant commercialization of these arts by magazines and the movie industry has had the effect of a massive advertising campaign. The resulting popular image of the martial arts, besides being ridiculously inaccurate, tends to appeal to people's violent and egotistical impulses. The martial arts expert is pictured in the mass media as a sort of superman who breaks bones with the greatest of ease and who is continually confronted with situations in which it is (or so the entertainment industry would have us believe) morally right to do so. The martial artist depicted in films, however, belongs to fantasy rather than reality. (1979, p. 101-102)

In contrast, martial arts in the East are not seen as a potentially violent pursuit but

rather as a philosophical one. Some influential branches of martial arts have specific rules concerning which body parts can or cannot be attacked, and actual combat is the very last choice. When combat must regrettably occur, martial artists should choose to retreat, or to simply subdue the opponent, avoiding harm or fatality. These codes and virtues illustrate clearly that, in the East, martial arts are not learned for the purpose of fighting. For Easterners, these formulae are clear and familiar truths; for many Westerners, however, they are unfamiliar and bewildering (Herrigel, 1989).

\section{Theoretical foundations of Eastern martial arts}

Although the styles, branches, and forms might differ, the intrinsic values, ethics, and virtues for all traditional Eastern martial arts are the same (Levine, 1984; Schmidt, 1986). Eastern martial arts are rooted in the Eastern philosophies, mainly Daoism 
(Taoism in English), Confucianism, and Buddhism (Xu, et al., 1996). In order to truly understand martial arts and their application to physical education, one must be aware of the philosophical principles upon which they are based. The main ones are: Dao, Ren, Li, $\mathrm{He}$, universe-human oneness, and martial virtue. In what follows, each of them will be explained briefly.

\section{Dao (道)}

Many readers may be familiar with Eastern martial arts that end with the Chinese suffix, "dao" (or "do"), (e.g., Japanese "judo" and Korean "taekwondo"). "Dao" in Chinese literally means way, path, road, regulation, or law. In traditional Eastern culture, what really matters is the "way" (process) of achieving a goal and not the goal itself"One is a martial artist only to the extent that one is always striving to become a better martial artist" (Monahan, 2007, p. 49). As such, Dao, as a "way" to truth, is a fundamental concept in Eastern philosophies and frequently used in Daoism (or Taoism), Confucianism, and Buddhism. Eastern martial arts also employ Dao as a "path" toward enlightenment and finding truth (Brown \& Johnson, 2000; Lu, 2006).

As Lao Zi explains, the "Dao" gives birth to Yin-Yang and eventually to everything in the universe. To Lao Zi, "Dao" is the "oneness" (Lao, 1994) and appears in the form of Qi. Everything in the universe originates from Qi (also called Yin-Yang Qi), and is the product of the change of Qi. In traditional Chinese philosophy, humans and nature are ingredients of an integral wholeness, which is regarded as the "human-nature integral view" (see more details in the section, "universe-human oneness" below). Fundamentally, everything in the universe - including human life-derives and evolves from the same root: Dao. Therefore, Dao is "one" that cannot be separated. (Martial Arts Administration Center, 1998)

Independent of human will, Dao exists in the universe as well as in every human being. As Cohn (1993) observes, the pursuit of traditional Eastern physical activities (e.g., martial arts) is an active step taken toward the Dao. These activities aim to:

make the body healthy, to extend its life span, and to open it up to the free flow of Tao. The Tao in its tangible form on earth is cosmic energy or Qi (Chi), a term hard to define and for which 'energy' is no more than a crude approximation. Qi is the vital power of the Tao at work in the world in nature, in society, in the human body. (p. 133)

According to traditional Chinese medicine, the fundamental cause of disease is violation of the Dao. Therefore, the treatment requires one to conform him/herself to the Dao and balance his/her Yin Qi and Yang Qi. The role of traditional martial arts is precisely to circularize, adjust, and balance Yin Qi and Yang Qi, and to eventually direct practitioners to a simple, natural, and healthy way of life - a oneness and harmony among all Yin-Yang relations ( $\mathrm{Lu}, 2006)$.

\section{“Ren”(仁), “Li” (礼), and “He”(和)}

Due to its great influence on Eastern society, Confucianism is central to Eastern martial arts in terms of value orientation and ethical judgment. The core of Confucianism is "Ren," which becomes the central spirituality of "martial virtues" or "martial morals." "Ren" can be interpreted as benevolence, humanity, or kindheartedness - a principle 
which suggests handling all human relationships using honesty, tolerance, respect, friendliness, sincerity, and love (Xu, et al., 1996).

"Ren" is emphasized and promoted within the constitutions and regulations in martial arts schools. Masters of Eastern martial arts follow the saying "there are no martial arts without virtues” (艺无德不立 in Chinese) (Jiang, Chen, Chen, Li, Sun, \& Qin, 1995, p. 64). It is a common practice for masters to focus on the enhancement of students' virtue and to pass on the finest and rarest knowledge and skills to the selected disciple who best demonstrates these virtues in daily life. Masters would rather let their superior martial arts become extinct than promote students with poor virtues (which is called 宁可失传, 不可轻传 in Chinese). Hence, in the practice of martial arts, “Ren" must always come first.

When Confucian thought departs from "Ren" and branches into combat and competition, "Li" (i.e., a conceptual system of courtesy, etiquette, and norms) must be applied. Confucius himself, in fact, discouraged competitions; however, when a competition must occur, it should be normalized by "Li" along with the principles of "Ren" (Xu, et al., 1996). Let us recall that the "Ren" ethic in Eastern martial arts is the manifestation of the pan-harmonious ethical thought, which refers to the value judgment which should ideally consider the concerns of the universe, nature, and humans on an equal basis (Xu, et al., 1996, p. 93). In fact, harmony in Chinese is directly associated with the concept of morals. Moreover, the core of the value judgment is "He" (harmony), and it is always the principal consideration because, as Lao Zi (sometimes written as Lao Tzu or Lao Tse), the founder of Daoist philosophy, claims: "All things bear the negative represented by Yin and face the positive represented by Yang; these two mingled in balance and created harmony" (Yang, 1987, p. 105). Confucianism regards "harmony" as the root of creation, and the prime element for the development of everything in nature.

In contrast to Western physical activities and sports that emphasize competition and seek personal value and identity through comparison, Eastern martial artists pursue harmony in the self between parts of the body, between breath and movement, and between body and mind. Harmony between the self and others, on the one hand, and between the self and the universe (including nature), on the other hand, is also highly valued (Lu \& Yuan, 1991). Moreover, martial arts instruct that harmony within the self is Zhen (truth), harmony between the self and others is Shan (benevolence), and harmony between the self and the universe is Mei (beauty). As it is of universal importance, the concept of "harmony" is the highest principle in ethical framework of martial arts $(\mathrm{Xu}$, et al., 1996).

\section{Universe-human oneness (天人合一)}

"Universe-human oneness" is believed to be the lofty realm referred to in Chinese philosophies to which all students of the Dao aspire. This concept teaches first that the universe and human beings are originally one and the same thing. Second, it instructs that the ideal or ultimate goal for humans is to consciously reach that "universe-human oneness" state where there is no difference between the self and anything else, and no separation between the inside and outside self (Jiang, et al., 1995). For martial arts practitioners, attaining the "universe-human oneness" is to access the oneness of Dao, harmony, and one's own heart and true self (Jiang, et al., 1995). For this, there seem to be two stages that secular practitioners must experience: from big self (i.e., self identity) to 
small self (i.e., the self as a diminutive part of nature as a whole); and from the small self to no self (i.e., the self as nature, and nature as self). This is why it is essential to practice martial arts outdoors, exposed to nature's changing seasons and various weather conditions.

As pointed out by Abernathy (1995), ancient Eastern cultures view nature as a source of inspiration or a model of being. In this, it becomes important to strengthen one's internal Qi (air and energy) by exchanging Qi inside and outside the body by developing the self-to-nature relationship. As a matter of fact, this is considered to be more critical to learning martial arts than merely developing the external techniques. Martial artists are not considered fully disciplined until their internal, external, bodymind and martial virtues and skills are developed. "Ren", Li", and "harmony" are all conceptual means to assist practitioners to find Dao toward this "universe-human oneness".

\section{Martial virtue (武德)}

Another principle in martial arts training is called, “内 (inside) 外 (outside) 兼 (both) 修 (cultivating)". “Inside” refers to morals, mind, or spirit; “outside” refers to physical strength or skills (Xu, et al., 1996). In Eastern martial arts, the external forms and skills can be taught; the artistic conception, however - the spirit, and the essence or the true meaning of the Dao in Eastern martial arts - can only be perceived from within (Xu, et al., 1996). Therefore, although it is essential to master the appropriate physical movements and martial skills, it is also crucial to train the mind or spirit by cultivating Qi. Without the "inside" training, the physical movement becomes futile. That is why martial arts practitioners are able to demonstrate morals such as respect, self-control, and self-discipline. Good morals stabilize one's emotions which, in turn, greatly benefit one's physical abilities and enhance one's overall martial arts learning. This integration of physical strength, Qi, mind, and spirit is a highly unique approach among physical activities and sports (Jiang, et al., 1995; Xu, et al., 1996).

What emphatically sets Eastern martial arts apart from Western physical sports is that the emphasis is placed on "martial virtues" rather than martial technical skills and abilities. In the East, practitioners are compelled to cultivate both internal morals and external physical strength and martial skills (Lu \& Yuan, 1991), and martial arts are considered to be an essential method of improving moral character. The ethical concept of Eastern martial arts is employed to regulate martial artists' actions and behavior in all aspects of life, and students' moral qualities are considered as a prerequisite for learning martial arts (Xu, et al., 1996). In this regard, many martial arts schools have explicit regulations about not accepting students who have certain undesirable moral problems (e.g., a desire for social destruction, aggressiveness, addiction to alcohol, boastfulness, financial greed, lack of diligence, a deficiency in loyalty or filial piety). Students in martial arts schools are guided to be respectful, self-controlled, self-responsible, and modest, and must live a simple and frugal life (Kauz, 1977). Therefore, being "engaged in martial arts promotes good moral character, promotes nonviolent attitudes and behavior, and leads to enlightenment" (Back \& Kim, 1979, p. 19).

In addition to the influence of Confucianism and Daoism, Buddhist principlessuch as respecting the liberty of all living things, and having a merciful and benevolent spirit-also have considerable impact on Eastern martial arts. The Shao Lin Buddhist 
temple, for example, has become synonymous with one of the most influential martial arts in the world. Representing the Ren thought in martial virtues, many Shao Lin martial arts masters stress employing virtues, rather than combative techniques or skills, to overpower and persuade an opponent (“大义服人, 以德感人,先礼后兵” in Chinese). This parallels the teachings of Sun $\mathrm{Zi}$, founder of the military school of philosophy, who advises that the highest level in combat is attained by overpowering one's opponents without fighting (Xu, et al., 1996).

When fighting is unavoidable, the non-violent disposition of Eastern martial arts dictates that an opponent's attack should not be resisted, but rather tactically remaneuvered in order to induce the attacker to lose his or her balance - a technical defeat. Further, this should be done with such finesse and delicacy that the attacker does not feel humiliated. The martial artist should not focus on being a winner, but show sincere courtesy and help the attacker get back on his or her feet. This scenario precisely demonstrates the virtues of "Ren", "Li", and "He" that a true martial artist possesses.

Martial arts are also considered as "a philosophy based on the belief that a sound mind is achieved through the development of a virtuous character" (Cerny, 1981, p. 49), and a high code of honor must be upheld at all times. As Schnurnberger (1987) reveals,

There is a recognizable cultural philosophy that is a part of martial arts. It is impossible to be deeply involved in martial arts and not be affected by the philosophy of nonviolence, of respect for your self and your opponent and the emphasis of becoming all you are capable of being" (p. 152).

Kauz (1977) also identifies the following components in Eastern martial arts virtue: 1) respect for life and nature, 2) Wu Wei (non-action), 3) moderation and balance, 4 ) education for training of one's character, 5) filial piety and conformity to the social order, 6) and transcendental spirit and enlightenment. Therefore, Eastern martial arts are a means to foster peace and moral education (Brawdy, 2001) — purposes which are quite the opposite of the way these arts are frequently portrayed in Western media. In fact, when examining the objectives and benefits listed in legitimate martial arts schools, it is apparent that their programs teach virtues such as respect, self-control, self-discipline, courage, caring, fidelity, integrity, and prudence through the training of self-defense (as well as other by-products such as concentration, fitness, relaxation, self-esteem, positive attitude, and stress management).

\section{Modern Westernized Eastern martial arts and deemphasized moral education}

Unfortunately, many modern martial arts, as practiced in the West, focus upon the Western value of physical competitiveness, with little or no emphasis on Eastern philosophy, meditation, mental discipline, or character development (Konzak \& Klavora, 1980). Back and Kim (1984) point out that Eastern martial arts are taught differently in the East and the West: elements indigenous to Eastern martial arts, such as spiritual development, are ignored by many Western practitioners and replaced with full contact training and a focal point of "winning"-a misled application of true Eastern martial arts. This is evidenced in the Yellow Pages advertisements of many commercial martial arts schools, which emphasize how many champions they have produced in various competitions.

Of course, this tendency to apply the "champion" mindset to one's pursuits is common practice in the West and there is plenty of sports dogma to back it up. In fact, a 
widely-quoted sports adage attributed to the American football coach Vince Lombardi holds that "winning isn't everything, it's the only thing" - a sentiment which succinctly captures the status that product holds over process in Western culture. Whereas victory is easily measurable when there is a medal or trophy attached to it, virtue as it is perceived by Eastern martial artists is more abstract, and may be more difficult for Western students to identify as an attainable goal.

The fact that many martial arts instructors do not support the addition of Eastern martial arts as Olympic sports is an example of their attempts to resist Western influences on the Eastern arts. These instructors feel that the Eastern martial arts should be practiced as a way to develop self-discipline, virtue, and health, so as to attain enlightenment and spiritual goals. Combativeness is only a means, not the goal itself. From this perspective, therefore, it appears absurd to try to achieve a real martial arts master's level using the Western concepts of "black belt" winners or combat champions.

These instructors' concerns are valid, because the format of competitive Eastern martial arts has in fact been substantially sportized. For example, Judo, Karate, Kung Fu (Wushu), Taekwondo, and many other martial arts have been redesigned to conform to Olympic "ideals." As a result, many of today's martial artists are similar to gymnasts, searching for an aesthetic in public exhibition and hunting for medals. Needless to say, this is a complete departure from the philosophical root of these arts which promotes selfenlightenment and a progression towards the Dao.

\section{Martial arts as a way to reduce violence in public schools}

Current physical education curricula are moving toward the development of students' necessary knowledge, skills, and attitudes that will lead to an active healthy lifestyle. A healthy lifestyle, furthermore, implies non-violence. Integrating martial arts with an Eastern philosophy into physical education programs may have several benefits. In addition to adding new vocabularies and broadening the spectrum of activities in school, martial arts incorporate knowledge and skills that can be integrated into one's lifelong repertoire and can help students become more mindful, reflective, deliberate, thoughtful, and disciplined.

In response, scholars and other educational professionals have proposed the inclusion of self-defense in Western school curricula (Carleton \& Chen, 1999; Lu, 2006; Reilly \& Friesen, 2001; Taylor, 1997). Carleton and Chen (1999) argue that "the unique contributions of physical and motor skill development within the school curriculum provided by physical education identifies these classes as the logical place for developing and teaching a self-defense unit" (p. 33). Currently, a self-defense unit usually integrates a variety of applied martial arts that provide multiple benefits: in addition to learning selfdefense skills and strategies, students learn to foster better health, tranquility, cultural awareness, self-esteem, self-control, fitness, self-confidence, concentration, and gender equity (Kwak, 1997; Lu, 2004; Reilly \& Friesen, 2001).

Also, I would be remiss were I not to mention the reality of school violence. A recent study by the National Center for Education Statistics (2006) of the United States Department of Education indicates that the percentage of public schools in the United States experiencing one or more violent incidents increased from $71 \%$ to $81 \%$ between the 1999-2000 and 2003-04 school years. In 2003-2004, roughly 88\% of public schools reported a total of 2.1 million crimes - a rate of 46 crimes per 1,000 students enrolled in 2003-2004. More than a quarter of the student population aged 12 to 18 years old $(28 \%)$ 
reported being bullied at school during the six months prior to this study. In Canada, the youth crime rate increased 3\% in 2006 (Statistics Canada, 2007) and more than 40\% of school boys and $20 \%$ of school girls reported that they had bullied others in the two months preceding a study by Pepler, Craig, Connolly, Yuile, McMaster, and Jiang (2005). Evidently, dealing with violence has become a serious issue in schools and in our society. Contrary to what may be thought, martial arts can be employed as a self-defense, as the mere fact of knowing martial arts may deter both the martial artist (the student, in this case) and possible attackers from engaging in a fight: in the case of the former, because he or she may feel more secure and know what to do to avoid the fight; in the case of the latter, because the mere knowledge that their "prey" knows martial arts may make them think twice about instigating a confrontation.

In other words, learning martial arts also helps at-risk children and youth through the core virtues of Eastern martial arts and martial education - a claim that has been supported by a number of studies (Blowers, 2007; Berry, 1991; Demoulin, 1987; Edelman, 1994; Glanz, 1994; Hellison, 1978; Mendenhall, 2006; Twemlow \& Sacco, 1998). Coincidentally, children and youth who planned to acquire martial arts training as a means of learning fighting techniques changed their attitudes because "the first thing which a student who seriously studies the martial arts discovers is that they involve an enormous amount of discipline and hard work" and "the second thing that is discovered is that far from turning one into an engine of destruction, oriental combative sports/arts develop self-control" (Min, 1979, p. 102). It has also been observed that students who studied martial arts did not get bullied anymore, not necessarily because they used martial arts to protect themselves or to frighten bullies, but because they transformed themselves in terms of enhancing their self-esteem, confidence, and demeanor through learning martial arts (Cox, 1993; Lu, 2004).

\section{Conclusion}

In the introduction to Herrigel's Zen: In the art of archery, Suzuki suggests that Eastern martial arts "are not intended to be for utilitarian purposes only or for pure aesthetic enjoyment, but are meant to train the mind; indeed, to bring it into contact with the ultimate reality...The mind has first to be attuned to be the Unconscious... One has to transcend technique so that the art becomes an 'artless art' growing out of the unconscious" (Herrigel, 1989, p. vii). Learning and practicing martial arts will not increase the aggression of violence; rather, it will enhance one's awareness of violence prevention and allow one to react calmly and without panic. This is evidenced in numerous empirical studies and, more importantly, anchored in the theoretical foundations of Eastern martial arts. Eastern martial arts represent the Eastern philosophy of Dao that strives for the harmony of self with the universe as an ultimate goal. This is in complete opposition to comparison or competition for the sake of self-realization or selfidentity. Martial virtues, primarily rooted in three schools of thought (Buddhism, Confucianism, and Daoism), allow practitioners to develop as true human beings with love, sincerity, and self-discipline. Thus, Eastern martial arts are a powerful pedagogical means to strengthen social harmony and simultaneously enhance the virtue of people and their understanding of nature, the self, and life. As such, martial arts may be an invaluable useful resource in public schools. 


\section{References}

Abernathy, S. E. (1995). Traditional Tae Kwon Do: A curriculum innovation for elementary physical education. Unpublished doctoral dissertation, Middle Tennessee State University, Murfreesboro, TN.

Back, A., \& Kim, D. (1979). Towards a Western philosophy of the Eastern martial arts. Journal of the Philosophy of Sport, 6, 19-28.

Back, A., \& Kim, D. (1984). The future course of the Eastern martial arts. Quest, 36, 714.

Berry, J. L. (1991). Yoshukai Karate: Curriculum innovation for at-risk youths. (ERIC Document Reproduction Service No. ED340678)

Blowers, J. G. (2007). Impact of an after-school martial arts program on at-risk students. Unpublished doctoral dissertation, Northcentral University, Prescott, AZ.

Brawdy, P. (2001). Exploring human kindness through the pedagogy of aikido. (ERIC Document Reproduction Service No. ED451451)

Brown, D., \& Johnson, A. (2000). The social practice of self-defense martial arts: Applications for physical education. Quest, 52, 246-259.

Carleton, N., \& Chen, G. (1999). Self-defense through physical education: Part I. Strategies, 12(5), 31-37.

Cerny, M. (1981). Understanding Karate. Journal of Physical Education, Recreation, and Dance, 52(7), 47-49.

Cohn, L. (Ed.). (1993). The Taoist experience: An anthology. Albany, NY: State University of New York

Cox, J. C. (1993). Traditional Eastern martial arts training: A review. Quest, 45, 366-388.

De Knop, P., Engstrom, L. M., Skirstad, B., \& Weiss, M. R. (Eds.). (1996). Worldwide trends in youth sport. Champaign, IL: Human Kinetics.

Demoulin, D.F. (1987). Juvenile delinquents, the martial arts and behavior modification: An experimental study for social intervention. (ERIC Document Reproduction Service No. ED291854)

Edelman, A. J. (1994). The implementation of a video-enhanced aikido-based school violence prevention training program to reduce disruptive and assaultive behaviors among severely emotionally disturbed adolescents. (ERIC Document Reproduction Service No. ED 384187)

Forster, A. (1986). The nature of martial arts and their change in the West. In S. Kleinman (Ed.), Mind and body: East meets West (pp. 83-87). Champaign, IL: Human Kinetics.

Glanz, J. (1994). A school/curricular intervention martial arts program for at-risk students. (ERIC Document Reproduction Service No. ED375347)

Hellison, D. (1978). Combatives for alienated youth: Problems and prospects. (ERIC Document Reproduction Service No. ED153987) 
Herrigel, E. (1989). Zen: In the art of archery (R. F. G. Hull, Trans.). New York: Vintage Books.

Jiang, B., Chen, Q., Chen, S., Li, J., Sun, H., \& Qin, Z. (1995). The theoretical foundations of $W u$ Shu. Beijing: People's Press of Sports.

Johnson, A., \& Brown, D. (2000). The social practice of self-defense martial arts: Applications of physical education. Quest, 52, 246-259.

Kauz, H. (1977). The martial spirit: An introduction to the origin, philosophy and psychology of the martial arts. New York: The Overlook Press.

Konzak, B., \& Klavora, P. (1980). Some social psychological dimensions of Karate participation: An examination of personality characteristics within the training context of a traditional martial art. In P. Klavora \& K. A. Wipper (Eds.), Psychological and sociological factors in sport (pp. 217-232). Toronto, Ontario: University of Toronto Press.

Kwak, E. C. (1997). Implementation of martial arts into secondary physical education program. Paper presented at the World Conference on Teaching, Coaching, and Fitness Needs in Physical Education and the Sport Sciences, Singapore.

Lao, Z. (1994). Wisdom of Laotse (Y. Lin, Trans.). Taipei, Taiwan: Zhengzhong Book Press.

Levine, P. N. (1984). The liberal arts and the martial arts. Liberal Education, 70, 235251.

Lu, C. (2004). East meets West: a cross-cultural inquiry into curriculum theorizing and development in physical education. Unpublished doctoral dissertation, the University of Alberta, Edmonton, Alberta, Canada.

Lu, C. (2006). Eastern and Western approaches to physical and health education. In E. Singleton \& A. Varpalotai (Eds.), Active theory for secondary school physical and health educators (pp.71-85). London, Ontario: The Althouse Press.

Lu, C., \& Yuan, L. (1991). The Eastern-Western cultural influence on physical education and sports. Journal of Shandong Medical University, 5(4), 64-67.

Martial Arts Administration Center (1998). Text for qi gong professional training. Martial Arts Administration Center of General Administration of Sport of China. Beijing: People's Press of Sports.

Mendenhall, M. (2006). An investigation of the impact of Buddhist martial arts as a rehabilitation intervention program to remedy emotional problems, curb aggressive tendencies, develop self-awareness, and cultivate a strong moral foundation with incarcerated juvenile delinquents. Unpublished doctoral dissertation, Saybrook Graduate School and Research Center, San Francisco, CA.

Min, H. K. (1979). Martial arts in the American education setting. Quest, 31 (1), 97-106.

Monahan, M. (2007). The practice of self-overcoming: Nietzschean reflections on the martial arts. Journal of the Philosophy of Sport, 34, 39-51.

National Center for Education Statistics. (2006). Indicators of school crime and safety: 
2006. Washington, D.C.: U.S. Department of Education (NCES 2007-003).

Pepler, D., Craig, W., Connolly, J., Yuile, A., McMaster, L., \& Jiang, D. (2005). A developmental perspective of bullying. Manuscript submitted. Retrieved November 26, 2007 from http://www.publicsafety.gc.ca/res/cp/bully_12217en.asp\#8

Reilly, E., \& Friesen, R. (2001). Incorporating self-defense into the physical education. Strategies, 14(6), 14-17.

Sasaki, T. (2006). The meaning and role of budo (the martial arts) in school education in Japan. Archives of Budo, 2, 11-14.

Schmidt, R. J. (1986). Japanese martial arts as spiritual education. In S. Kleinman (Ed.), Mind and body: East meets West (pp. 69-74). Champaign, IL: Human Kinetics.

Schnurnberger, L. (1987). Those terrific Karate kids. Parents, 62(11), 150-154.

Statistics Canada. (2007). Crime statistics: 2006. Retrieved November 26, 2007 from http://www.statcan.ca/Daily/English/070718/d070718b.htm

Taylor, D. (1997). You can teach self-defense in your classes-No experience necessary. Teaching Secondary Physical Education, 3, 27-28.

Theeboom, M., \& De Knop, P. (1999). Eastern martial arts and approaches of instruction in physical education. European Journal of Physical Education, 4, 146-161.

Twemlow, S. W., \& Sacco, F. C. (1998). The application of traditional martial arts practice and theory to the treatment of violent adolescents. Adolescence, 33, 505518.

$\mathrm{Xu}, \mathrm{C}$., et al. (1996). Introduction to the discipline of Wu Shu. Beijing: People's Press of Sports.

Yang, J. (1987). Lao-Tze Tao Te Ching. Taipei, Taiwan: Lao-Zhuang Society. 
Table: Terms in Chinese characters and translation used in the article

\begin{tabular}{|c|c|c|}
\hline Terminology & $\begin{array}{l}\text { Chinese } \\
\text { Characters }\end{array}$ & Translation \\
\hline Dao (aka, Tao) & 道 & $\begin{array}{l}\text { - } \quad \text { the "way" or "path" } \\
\text { - law or regulation of the universe }\end{array}$ \\
\hline $\mathrm{He}$ & 和 & - harmony \\
\hline $\mathrm{Li}$ & 礼 & - system of courtesy, etiquette and norms \\
\hline Mei & 美 & - beauty \\
\hline Qi (aka, Chi) & 气 & - energy, life force, air \\
\hline Ren & 仁 & $\begin{array}{l}\text { virtues, morals (e.g., humanity, } \\
\text { kindheartedness) }\end{array}$ \\
\hline Shan & 善 & - benevolence \\
\hline Wu Wei & 无为 & - non-action, action without action; \\
\hline Yin-Yang & 阴阳 & $\begin{array}{l}\text { - two mutually interdependent opposites (e.g., } \\
\text { moon/sun, female/male, cold/warm) }\end{array}$ \\
\hline Zhen & 真 & - truth \\
\hline
\end{tabular}

